\title{
Combined Effect of Slip Velocity and Surface Roughness on a Magnetic Squeeze Film for a Sphere in a Spherical Seat
}

\author{
G. M. Deheri and Sejal J. Patel \\ Department of Mathematics, Sardar Patel University, Vallabh Vidhyanagar, Gujarat 388120, India \\ Correspondence should be addressed to Sejal J. Patel; sejal.patel85@yahoo.com
}

Received 18 May 2015; Accepted 26 July 2015

Academic Editor: Pradeep Lancy Menezes

Copyright ( 2015 G. M. Deheri and S. J. Patel. This is an open access article distributed under the Creative Commons Attribution License, which permits unrestricted use, distribution, and reproduction in any medium, provided the original work is properly cited.

This investigation analyzes the performance of a magnetic fluid based squeeze film for a sphere in a rough spherical seat with slip velocity. The slip model of Beavers and Joseph has been deployed to study the effect of velocity slip while the stochastic model of Christensen and Tonder has been used to calculate the effect of surface roughness. The concerned statistically averaged Reynolds' type equation is solved to derive the pressure distribution which results in the calculation of load carrying capacity. The results presented in graphical forms confirm that the adverse effect of slip velocity can be overcome to a large extent at least in the case of negatively skewed roughness. However, lower values of slip may be preferred for enhancing the performance characteristics of the bearing system. Besides, variance (-ve) provides a little support to improve the performance characteristics.

\section{Introduction}

During the last two decades the magnetic fluid flow has drawn considerable interest for the applications to various engineering and industrial problems. The magnetic field plays a crucial role in positioning and controlling the tribological behaviour.

Bhat and Deheri [1] studied the effect of magnetic fluid on the action of a curved squeeze film existing between two circular disks. The effects due to magnetization were independent of the curvature of the upper disk. Jan [2] analyzed the experimental data for the lubricated bearings of precision and concluded that magnetic field altered the energetic state of equilibrium occurring in spinning friction of slides. Lin et al. [3] discussed the squeeze film characteristics of parallel circular disks lubricated by a ferrofluid with nonNewtonian couple stresses. Comparing with the Newtonian nonferrofluid case, the non-Newtonian ferrofluid lubricated squeeze film provided a higher load carrying capacity and lengthened the response time.

The effect of surface roughness has drawn considerable attentions during the last decade because of its effect on hydrodynamic lubrication as, in practice, most of the bearing surfaces are rough to certain extent. The random character of surface roughness has been very well recognized.

Stochastic model of Tzeng and Saibel [4] was developed by Christensen and Tonder [5-7] to study the effect of surface roughness. Prajapati [8] dealt with the combined effect of surface roughness and deformation on the squeeze film behavior between rotating porous circular plates with a concentric circular pocket. The introduction of the pocket reduced the load carrying capacity of the bearing. Gupta and Deheri [9] analyzed the performance of a hydrodynamic squeeze film between a nonrotating spherical surface and a hemispherical bearing under a steady load. It was observed that the composite roughness of the surfaces affected the performance characteristics significantly. Andharia et al. [10] dealt with the effect of transverse surface roughness on the performance of a squeeze film in a spherical bearing. The transverse roughness of the bearing surfaces affected the behavior of the bearing system, by reducing load carrying capacity. Andharia et al. [11] analyzed the effect of longitudinal surface roughness on the performance of a hydrodynamic squeeze film in a spherical bearing. Here, the situation was relatively better as 
compared to [10] dealing with transverse surface roughness. Naduvinamani et al. [12] presented a theoretical study on the effect of surface roughness on the hydrodynamic lubrication of couple stress squeeze film between a sphere and a flat plate. The load carrying capacity and squeeze film time were found to be increased for an azimuthal roughness pattern.

Pylios and Shepherd [13] applied the performance characteristics of spherical bearing system for the prediction of lubrication regimes in wrist implants with spherical bearing surfaces.

By making use of numerical network simulation method, Zueco and Bég [14] analyzed numerically the hydromagnetic squeeze film between two rotating disks. Lin [15] studied the effect of inertia forces on the non-Newtonian couple stress squeeze film between a sphere and a flat plate. The consideration of fluid inertia forces provided a longer squeeze film time especially for the squeeze film operating with a lower film height and a larger non-Newtonian parameter. Patel and Deheri [16] studied the performance of ferrofluid lubrication of a squeeze film in rough porous parallel circular disks, considering slip velocity. It was observed that the variance (-ve) provided assistance to magnetization in overcoming the negative effect of porosity and standard deviation associated with roughness.

Beavers and Joseph [17] constructed a simple theory to replace the effect on the boundary layer, with a slip velocity proportional to the exterior velocity gradient. The result obtained from this theory was found to be in good agreement with the experimental results. Hai [18] analyzed the effect of velocity slip on the squeeze film lubrication between porous rectangular plates. The presence of slip velocity decreased the load carrying capacity and response time. Sparrow et al. [19] discussed the effect of velocity slip on porous-walled squeeze films. Substantially faster response could be attained by the use of porous materials which accentuate velocity slip. Prakash and Vij [20] presented the effect of slip velocity on the squeeze film between rotating porous annular disks. The effect of slip was to reduce the load carrying capacity and the response time of the squeeze film. Patel [21] investigated the effect of velocity slip on the hydromagnetic squeeze film between porous circular disks. The load carrying capacity was found to be decreased when the slip parameter increased. Yacout et al. [22] analyzed the combined effect of centripetal inertia and the surface roughness on the hydrostatic thrust spherical bearings performance. Here, minimization of some of the roughness parameters was essential for the optimal performance. Patel and Deheri [23] studied the effect of surface roughness on the performance of a magnetic fluid based parallel plate porous slider bearing with slip velocity. It was established that the slip velocity caused reduced load carrying capacity but the friction remained unaltered. Patel and Deheri [24] dealt with the effect of slip velocity on the performance of a short bearing lubricated with a magnetic fluid. It was established that, for large values of aspect ratio, the effect of slip was increasingly significant.

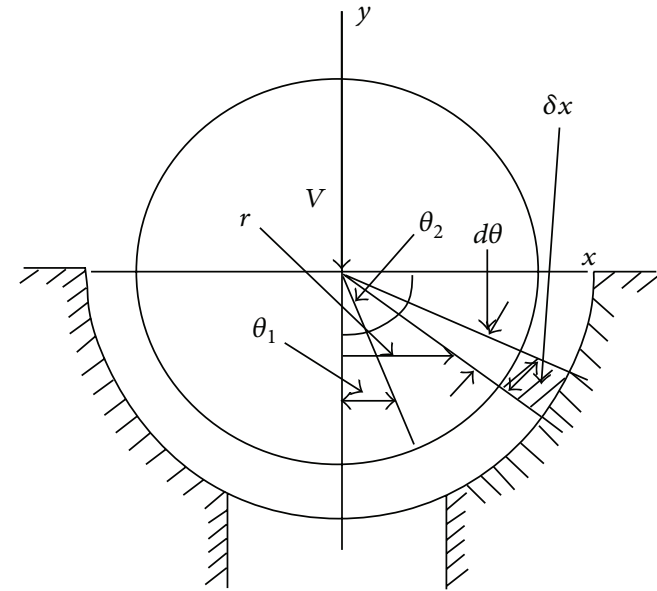

Figure 1: A sphere in a spherical seat.

Patel and Deheri [25] analyzed the effect of slip velocity and roughness on the performance of Jenkins model based magnetic squeeze film in curved rough circular plates. It was noticed that the Jenkins model moved ahead of NeuringerRosensweig model for reducing the adverse effect of roughness. Patel and Deheri [26] presented the effect of slip velocity and surface roughness on the behavior of Jenkins model based magnetic squeeze film in curved rough circular plates. This study suggested that, for any type of improvement in the performance characteristics, the slip parameter was required to be reduced even if variance (-ve) occurred and suitable magnetic strength was in force.

Recently, Deheri et al. [27] considered the effect of transverse surface roughness on the ferrofluid lubrication of squeeze film for a sphere in a spherical seat. It was found that the adverse effect of roughness could be minimized by the ferrofluid lubrication in the case of negatively skewed roughness.

Here, it has been proposed to discuss the effect of slip velocity on the above geometrical configuration of the bearing system.

\section{Analysis}

The geometry and configuration of the bearing system are given in Figure 1.

It consists of a sphere with radius $r$ in a hemispherical seat. The amount of flow from the control volume due to Poiseuille and Couette flow can be derived as (Majumdar, [28])

$$
\frac{-\pi}{6 \eta} \frac{d}{d x}\left(r h^{3} \frac{d p}{d x}\right) \delta x-\pi V \frac{d}{d x}(r h \sin \theta) \delta x,
$$

where $\eta$ is the viscosity of the lubricant, $h$ is the film thickness, and $V$ is the squeeze velocity $h$. The rate of reduction of flow due to squeeze action comes out to be

$$
2 \pi r V \cos \theta \delta x \text {. }
$$


Equating the total flow rate from the control section to the rate of reduction in volume of control space, one comes across

$$
\frac{d}{d x}\left(r h^{3} \frac{d p}{d x}\right)+6 \eta V \frac{d}{d x}(r h \sin \theta)=-12 \eta V r \cos \theta
$$

As

$$
6 \eta V \frac{d}{d x}(r h \sin \theta)
$$

is very small compared to the other terms, it can be neglected. Again, since $x=R \theta$ and

$$
r=R \sin \theta
$$

one concludes that

$$
\frac{d}{d \theta}\left(h^{3} \sin \theta \frac{d p}{d \theta}\right)=-6 \eta R^{2} V \sin 2 \theta .
$$

It is assumed that the flow in the porous region is governed by Darcy's law, which transforms (6) into

$$
\frac{d}{d \theta}\left(\sin \theta\left(h^{3}+12 \varphi H\right) \frac{d p}{d \theta}\right)=-6 \eta R^{2} V \sin 2 \theta
$$

where $\varphi$ is the permeability and $H$ is the thickness of porous facing.

In order to describe the steady flow of magnetic fluids in the presence of slowly changing magnetic fields a mathematical model was proposed by Neuringer and Rosensweig in [29]. Application of this model and related aspects regarding lubrication has been discussed in Bhat [30], Prajapati [31], and Bhat and Deheri [1]; with the use of magnetic fluid, (7) assumes the form

$$
\begin{aligned}
& \frac{d}{d \theta}\left(\sin \theta\left(h^{3}+12 \varphi H\right) \frac{d}{d \theta}\left(p-\frac{\mu_{0} \bar{\mu}}{2} H^{2}\right)\right) \\
& \quad=-6 \eta R^{2} V \sin 2 \theta,
\end{aligned}
$$

where $\mu_{0}$ is magnetic permeability, $\bar{\mu}$ is magnetic susceptibility, and

$$
M^{2}=K R^{2} \cos \theta
$$

wherein $K$ is a suitably chosen constant for obtaining a magnetic fluid of desired strength.

The bearing surfaces are considered transversely rough. According to the stochastic model of Christensen and Tonder [5-7], the thickness $h$ of the lubricant film is assumed as

$$
h=\bar{h}+h_{s}
$$

In this equation $\bar{h}$ denotes the mean film thickness and $h_{s}$ represents the deviation from the mean film thickness characterizing the random roughness of the bearing surfaces. $h_{s}$ is governed by the probability density function:

$$
f\left(h_{s}\right)= \begin{cases}\frac{35}{32 c^{7}}\left(c^{2}-h_{s}^{2}\right)^{3}, & -c \leq h_{s} \leq c \\ 0, & \text { elsewhere }\end{cases}
$$

wherein $c$ is the maximum deviation from the mean film thickness. The mean $\alpha$, the standard deviation $\sigma$, and the parameter $\varepsilon$, which is the measure of symmetry of the random variable $h_{s}$, are defined by the relationships

$$
\begin{aligned}
\alpha & =E\left(h_{s}\right), \\
\sigma^{2} & =E\left[\left(h_{s}-\alpha\right)^{2}\right], \\
\varepsilon & =E\left[\left(h_{s}-\alpha\right)^{3}\right],
\end{aligned}
$$

where $E$ denotes the expected value defined by

$$
E(R)=\int_{-c}^{c} R f\left(h_{s}\right) d s
$$

Skewness is a useful parameter in defining variables with an asymmetric spread and represents the degree of symmetry of density function. It is well established that positive skewness results in lower real area of contact and meniscus, while the negative skewness does the opposite. For the details regarding skewness one can cast a glance at [32].

Now, stochastically averaging (8) in the light of Christensen and Tonder's method [5-7] one is led to

$$
\frac{d}{d \theta}\left(\sin \theta g(h) \frac{d}{d \theta}\left(p-\frac{\mu_{0} \bar{\mu}}{2} H^{2}\right)\right)=-6 \eta R^{2} V \sin 2 \theta,
$$

where

$$
\begin{aligned}
g(h)= & h^{3}+3\left(\sigma^{2}+\alpha^{2}\right) h+3 h^{2} \alpha+\alpha^{3}+3 \sigma^{2} \alpha+\varepsilon \\
& +12 \varphi H
\end{aligned}
$$

while $\sigma$ is the standard deviation, $\alpha$ is the variance, and $\varepsilon$ is the measure of symmetry of the random roughness. The details regarding these parameters can be obtained from Christensen and Tonder [5-7].

The following nondimensional quantities are introduced:

$$
\begin{aligned}
& \bar{h}=\frac{h}{C}=1-e \cos \theta, \\
& P=\frac{C^{3} e}{\eta R^{2} V} p,
\end{aligned}
$$




$$
\begin{aligned}
\mu^{*} & =\frac{k \mu_{0} \bar{\mu} C^{3} e}{\eta V}, \\
\bar{\alpha} & =\frac{\alpha}{C} \\
\bar{\sigma} & =\frac{\sigma}{C} \\
\bar{\varepsilon} & =\frac{\varepsilon}{C^{3}} \\
\bar{\psi} & =\frac{\varphi H}{C^{3}},
\end{aligned}
$$

$C$ being the radial clearance and $e$ the eccentricity ratio.

In the fluid dynamics, the no-slip condition for viscous fluids states that, at a solid boundary, the fluid will have zero velocity relative to the boundary. But it was noticed that this phenomenon was not always true. The fluid will have some velocity relative to the solid boundary; this velocity is defined as slip velocity. By considering the velocity slip on porouswalled squeeze film, it was found that faster response of the squeeze time was in place, for suitable values of slip velocity.

The "no-slip" is a fundamental assumption and generally accepted boundary condition in rheology, tribology, and fluid mechanics with strong experimental support. The violations of this condition, however, are widely recognized in many situations, especially in the flow of non-Newtonian fluids. In the flow of viscous fluids over solid surfaces, the "noslip" at the fluid-solid interface is a widely accepted boundary condition with many important consequences. The essence of this condition is the continuity of the tangential component of the velocity at the wall due to the fact that viscous fluids stick to the solid surface. Strictly speaking, no-slip means that the instantaneous relative velocity between the fluid and surface, as well as its time average, is zero.
Lastly, making use of (Beavers and Joseph [17]) slip model with these above nondimensional quantities, the associated Reynolds' type equation turns out to be

$$
\begin{aligned}
& \frac{d}{d \theta}\left(\operatorname { s i n } \theta \left[\left(\frac{4+\bar{S}}{2+\bar{S}}\right)+3\left(\bar{\sigma}^{2}+\bar{\alpha}^{2}\right)\left(\frac{4+\bar{S}}{2+\bar{S}}\right)^{1 / 3}\right.\right. \\
& +3 \bar{\alpha}\left(\frac{4+\bar{S}}{2+\bar{S}}\right)^{2 / 3} \\
& \left.+\left(3 \bar{\sigma}^{2} \bar{\alpha}+2 \bar{\alpha}^{3}+\bar{\varepsilon}+12 \bar{\psi}\right)\left(\frac{2+\bar{S}}{1+\bar{S}}\right)\right] \frac{d}{d \theta}(P \\
& \left.\left.-\frac{\mu^{*}}{2} \cos \theta\right)\right)=-6 e \sin 2 \theta,
\end{aligned}
$$

where

$$
\bar{S}=s h .
$$

Integration of this equation with the boundary conditions

$$
\begin{aligned}
P & =0, \\
\theta & =\frac{\pi}{2}, \\
\frac{d P}{d \theta} & =0, \\
\theta & =0 .
\end{aligned}
$$

gives the expression for nondimensional pressure distribution as

$$
\begin{aligned}
P & =\frac{\mu^{*}}{2} \cos \theta \\
& +6\left\{\frac{(1-\bar{h})}{\left[((4+\bar{S}) /(2+\bar{S}))+3\left(\bar{\sigma}^{2}+\bar{\alpha}^{2}\right)((4+\bar{S}) /(2+\bar{S}))^{1 / 3}+3 \bar{\alpha}((4+\bar{S}) /(2+\bar{S}))^{2 / 3}+\left(3 \bar{\sigma}^{2} \bar{\alpha}+2 \bar{\alpha}^{3}+\bar{\varepsilon}+12 \bar{\psi}\right)((2+\bar{S}) /(1+\bar{S}))\right]}\right\} .
\end{aligned}
$$

Then, the expression for nondimensional load carrying capacity is calculated as

$$
\begin{aligned}
W & =\frac{C^{3} e}{\pi \eta R^{4} V} w=\frac{\mu^{*}}{3} \\
& +\frac{4 e}{\left[((4+\bar{S}) /(2+\bar{S}))+3\left(\bar{\sigma}^{2}+\bar{\alpha}^{2}\right)((4+\bar{S}) /(2+\bar{S}))^{1 / 3}+3 \bar{\alpha}((4+\bar{S}) /(2+\bar{S}))^{2 / 3}+\left(3 \bar{\sigma}^{2} \bar{\alpha}+2 \bar{\alpha}^{3}+\bar{\varepsilon}+12 \bar{\psi}\right)((2+\bar{S}) /(1+\bar{S}))\right]} .
\end{aligned}
$$




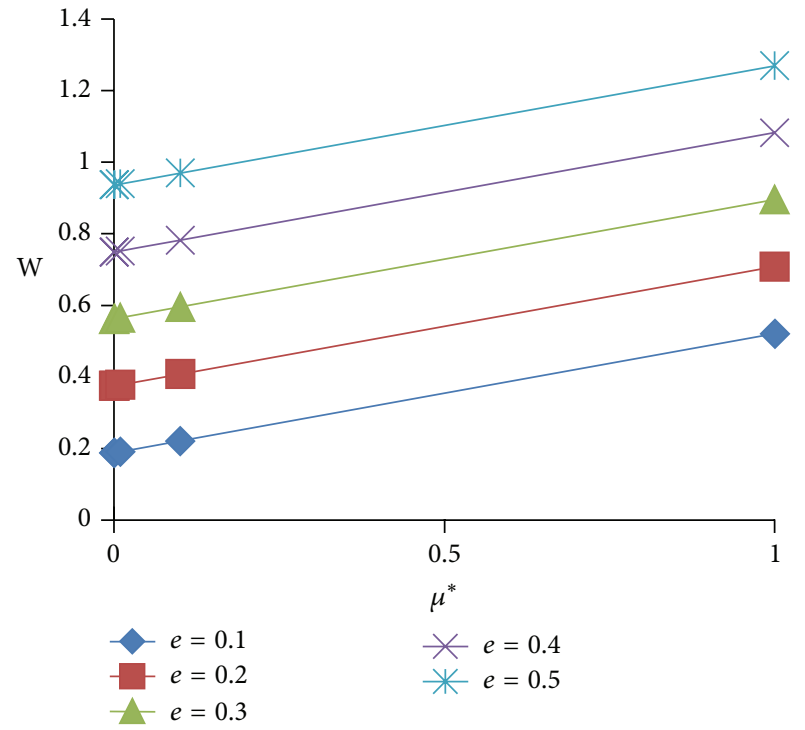

FIgURE 2: Variation of load carrying capacity with respect to $\mu^{*}$ and $e$.

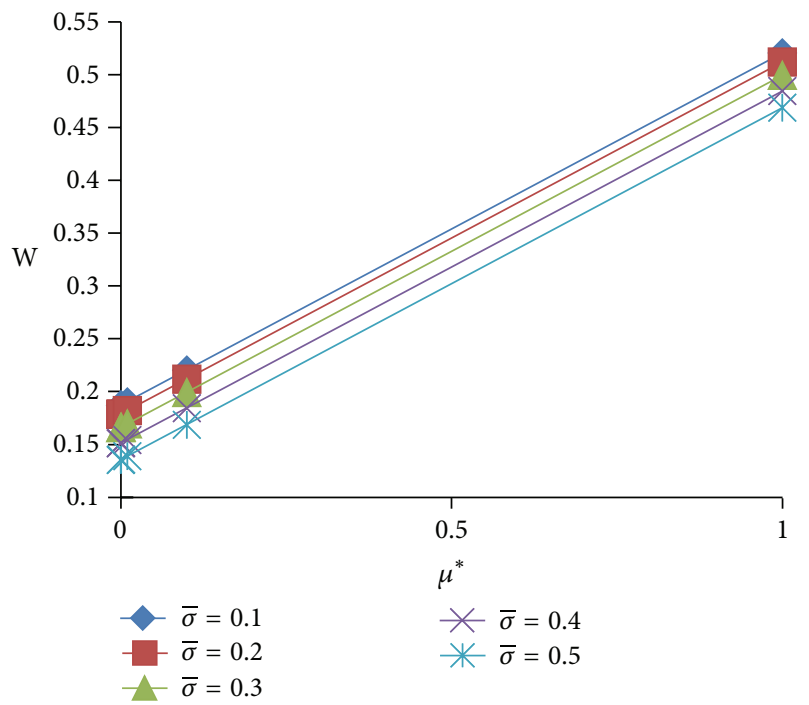

FIGURE 3: Variation of load carrying capacity with respect to $\mu^{*}$ and $\bar{\sigma}$.

\section{Results and Discussion}

It is noticed from (20) that the nondimensional pressure distribution is enhanced by

$$
\frac{\mu^{*}}{2} \cos \theta
$$

while the dimensionless load carrying capacity gets increased by

$$
\frac{\mu^{*}}{3}
$$

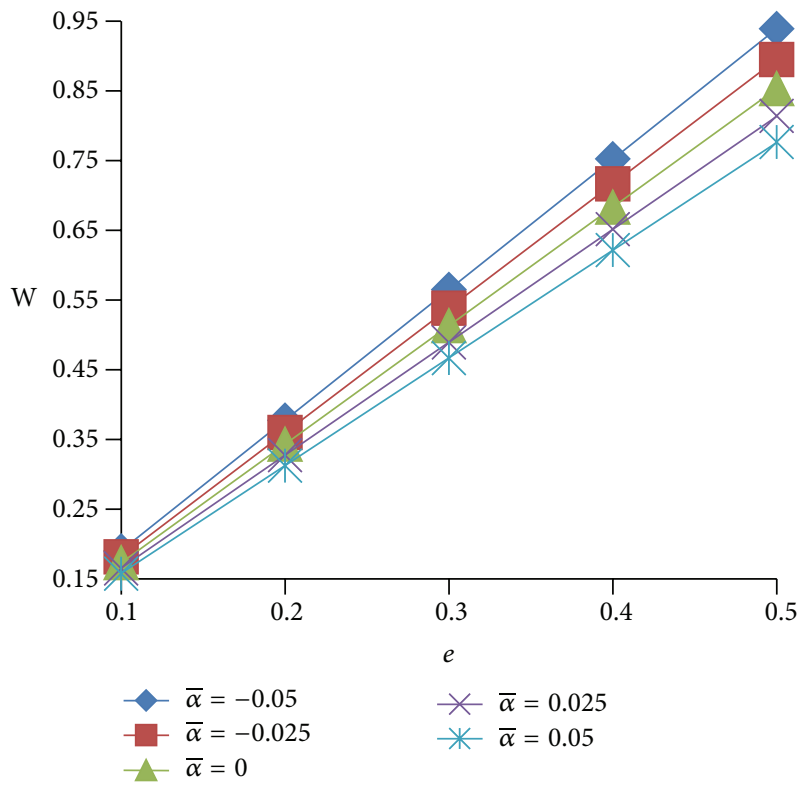

FIGURE 4: Variation of load carrying capacity with respect to $e$ and $\bar{\alpha}$.

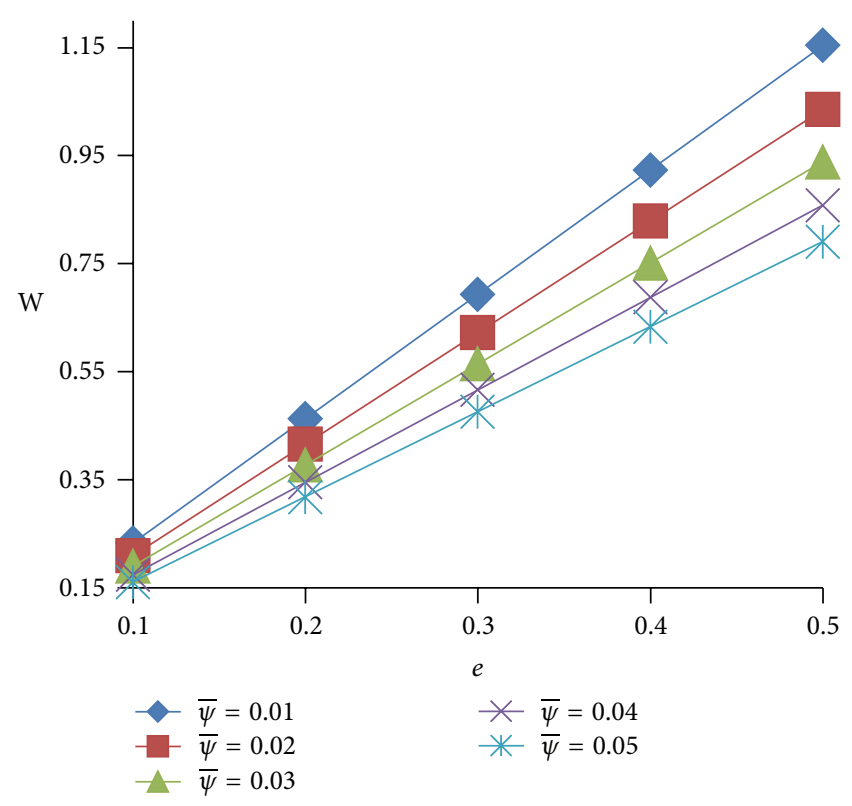

FIGURE 5: Variation of load carrying capacity with respect to $e$ and $\bar{\psi}$.

as can be seen from (21), in comparison with the conventional lubricant based bearing system. This is not surprising as the magnetization increases the viscosity of lubricant. Besides, one can see that the expression involved in (20) is linear with respect to $\mu^{*}$. Thus, an increase in $\mu^{*}$ would lead to increased load carrying capacity. This can be seen from Figures 2-3.

The variation of load carrying capacity with respect to $e$ presented in Figures 4-5 makes it clear that the load carrying capacity gets increased sharply owing to the eccentricity. 


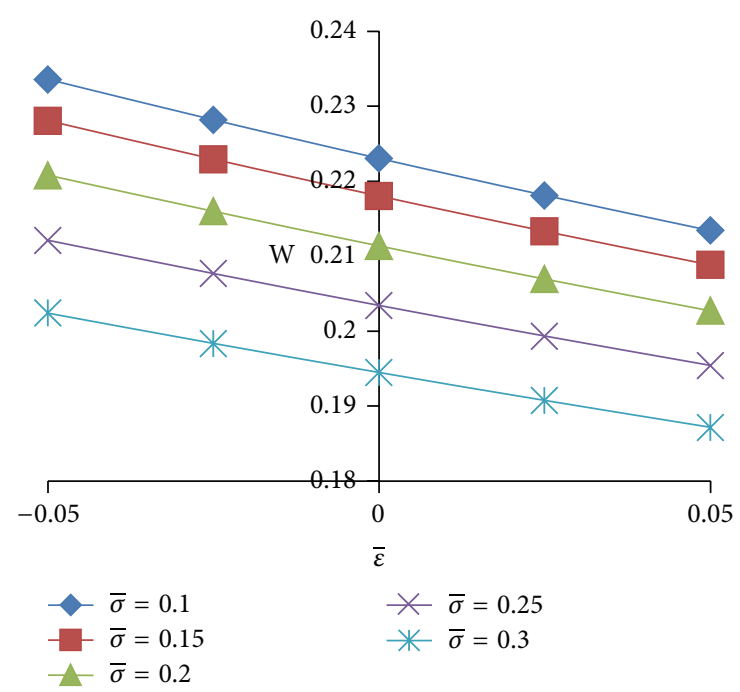

FIGURE 6: Variation of load carrying capacity with respect to $\bar{\varepsilon}$ and $\bar{\sigma}$

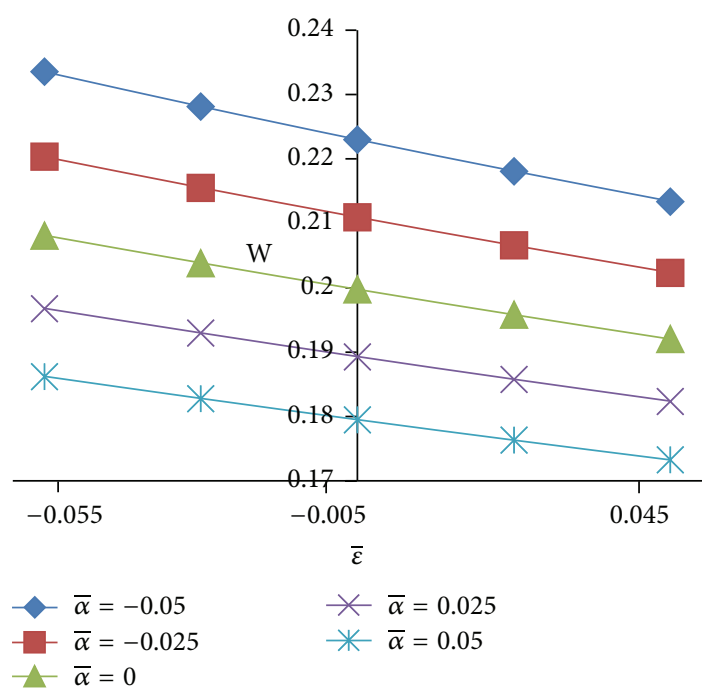

FIGURE 7: Variation of load carrying capacity with respect to $\bar{\varepsilon}$ and $\bar{\alpha}$.

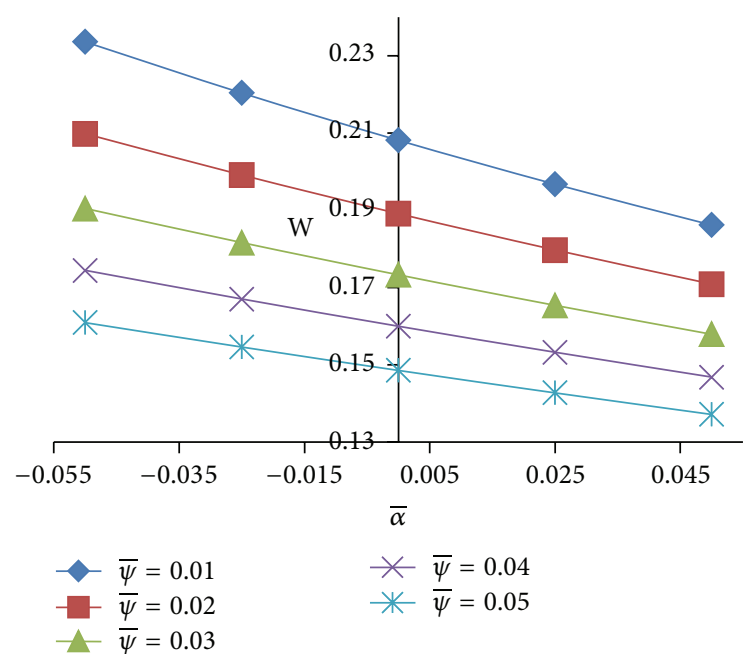

FIGURE 8: Variation of load carrying capacity with respect to $\bar{\alpha}$ and $\bar{\psi}$.

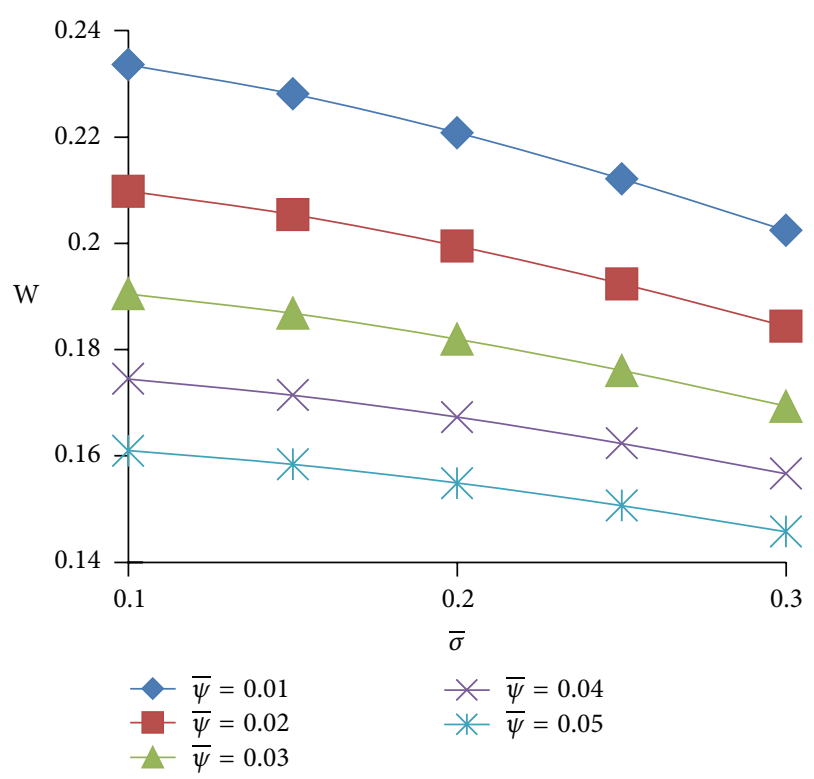

FIGURE 9: Variation of load carrying capacity with respect to $\bar{\sigma}$ and $\bar{\psi}$.

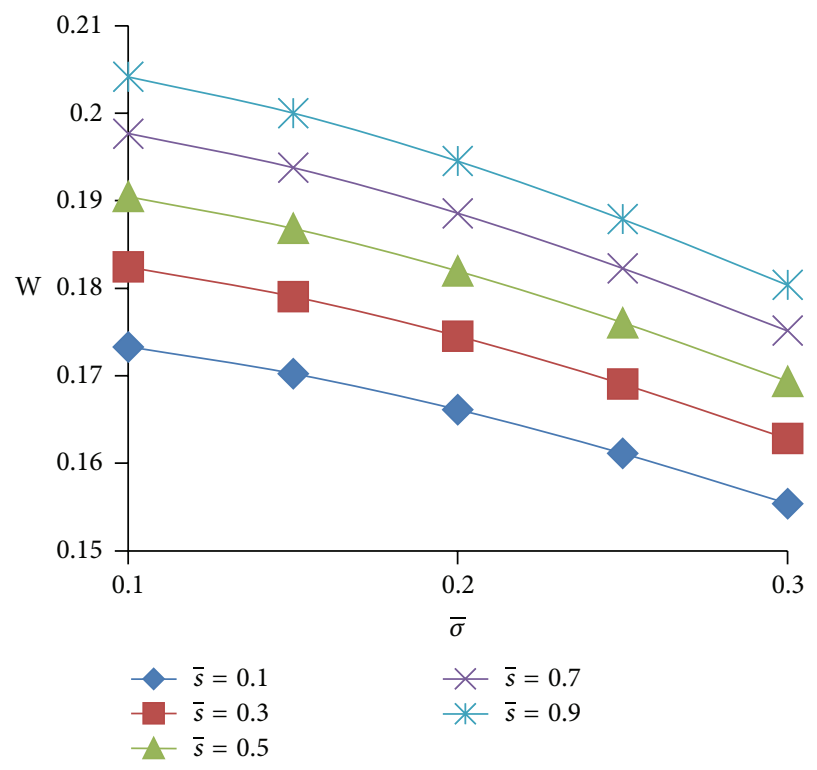

FIGURE 10: Variation of load carrying capacity with respect to $\bar{\sigma}$ and $\bar{s}$.

Figures 6-7 establish that the negatively skewed roughness increases the load carrying capacity while the load carrying capacity gets decreased due to positively skewed roughness.

Figure 8 indicates that the trends of load carrying capacity with respect to variance are almost similar to that of skewness. In other words, the increased load carrying capacity due to variance $(-\mathrm{ve})$ gets further increased owing to negatively skewed roughness.

Figure 9 establishes that the combined effect of porosity and standard deviation is to reduce the load carrying capacity. 


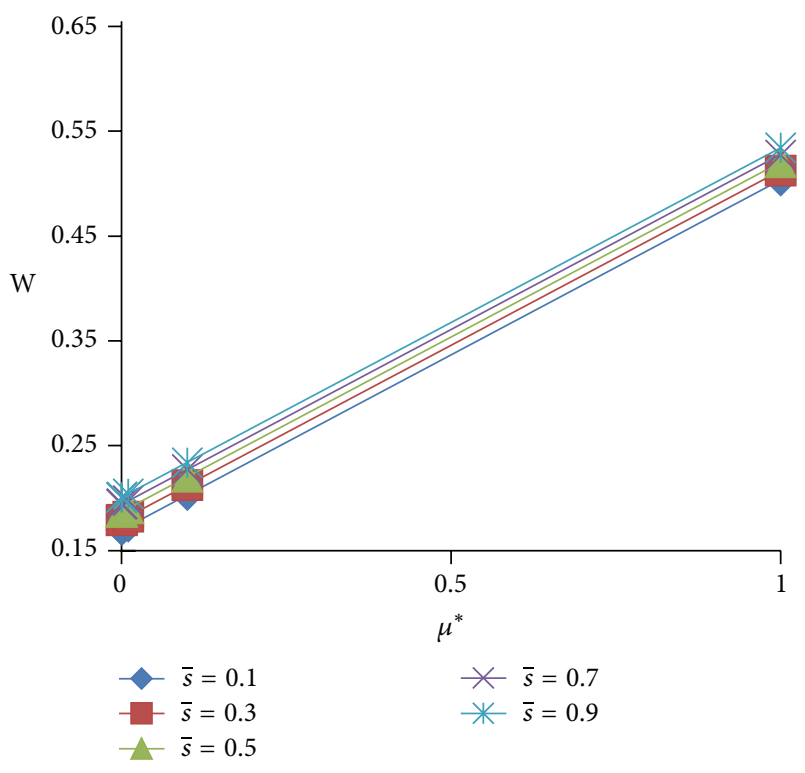

FIGURE 11: Variation of load carrying capacity with respect to $\mu^{*}$ and $\bar{s}$.

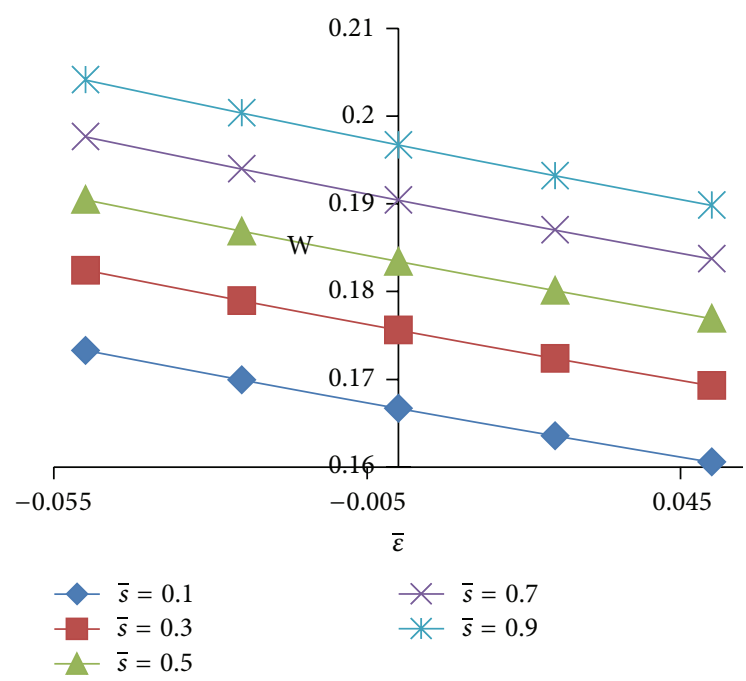

FIGURE 12: Variation of load carrying capacity with respect to $\bar{\varepsilon}$ and $\bar{s}$.

Indeed, Figures 10-15 display the effect of slip velocity. It is easily found that slip effect causes considerable load reduction in all circumstances. It is appealing to note from Figure 11 that the effect of slip on the distribution of load carrying capacity with respect to magnetization is nominal.

Although this investigation more or less reduces to the discussion of Deheri et al. [27] in the absence of slip, a comparison of this paper with that of Deheri et al. [27] indicates that the effect of slip velocity is not that sharp as a suitable choice of magnetic strength does not allow the load carrying capacity to fall rapidly owing to slip effect for this type of bearing system.

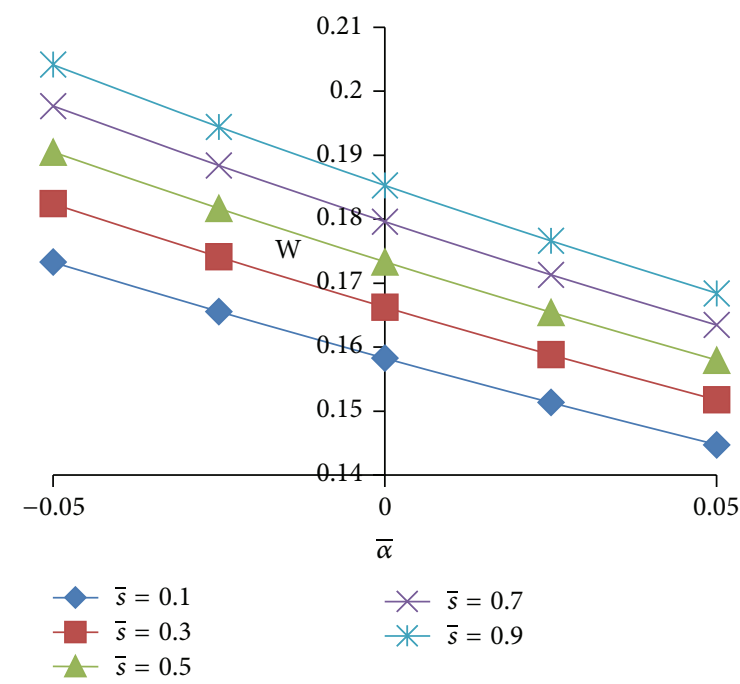

FIGURE 13: Variation of load carrying capacity with respect to $\bar{\alpha}$ and $\bar{s}$.

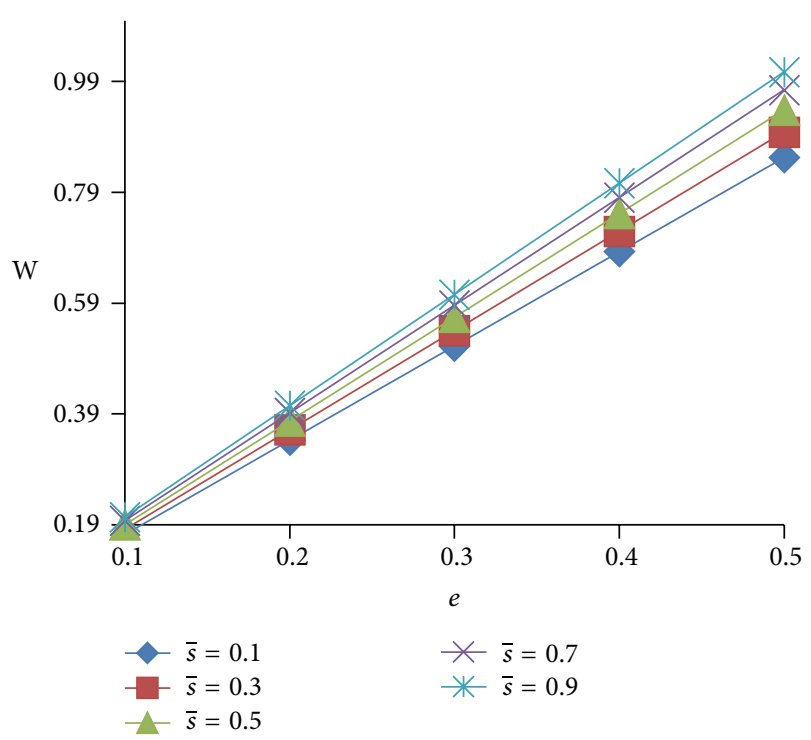

FIGURE 14: Variation of load carrying capacity with respect to $e$ and $\bar{s}$.

\section{Conclusion}

This paper affirms that for any type of improvement in the bearing performance the slip deserves to be at the reduced level. This investigation reveals that the roughness aspect must be evaluated while designing the bearing system, in view of the life period, as the combined effect of the trio the standard deviation, the porosity, and the slip causes severe load reduction. In spite of that there is a good amount of load supported by the bearing system, even in the absence of flow which does not happen for conventional lubricant based bearing system. Although the magnetization increases the load carrying capacity sharply, only it can go to a limited extent in minimizing the adverse effect of roughness, porosity, and slip. 


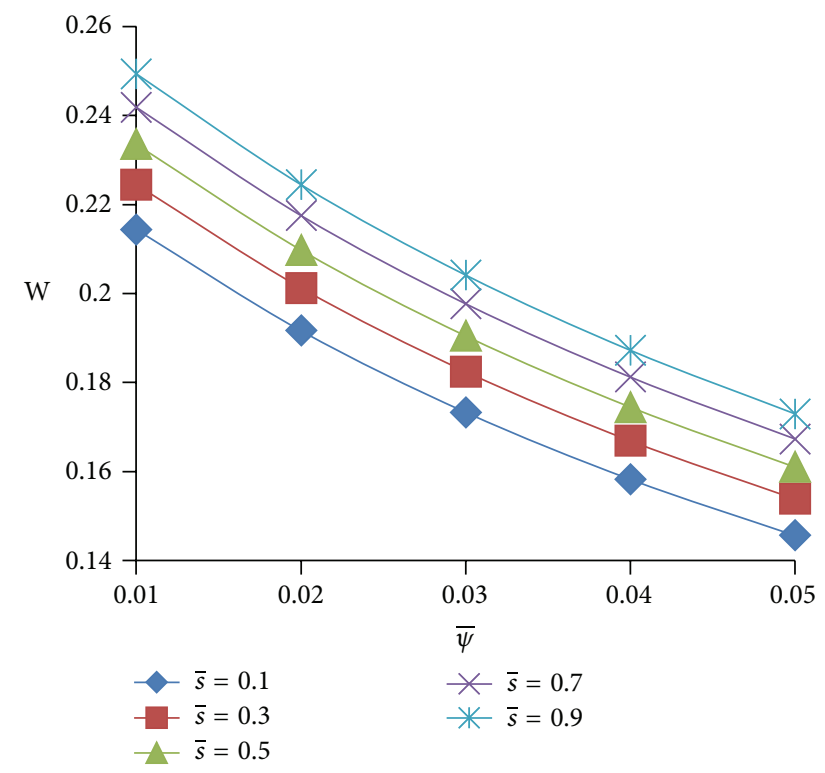

FIGURE 15: Variation of load carrying capacity with respect to $\bar{\psi}$ and $\bar{s}$.

However, the situation remains fairly improved in the case of negatively skewed roughness when variance $(-\mathrm{ve})$ occurs.

\section{Conflict of Interests}

The authors declare that there is no conflict of interests regarding the publication of this paper.

\section{Acknowledgments}

The authors acknowledge with thanks the fruitful comments and suggestions of the reviewers/editors.

\section{References}

[1] M. V. Bhat and G. M. Deheri, "Magnetic-fluid-based squeeze film in curved porous circular discs," Journal of Magnetism and Magnetic Materials, vol. 127, no. 1-2, pp. 159-162, 1993.

[2] B. Jan, "Investigation on magnetic fluids as lubricant," Indian Journal of Engineering and Materials Sciences, vol. 11, no. 4, pp. 338-342, 2004.

[3] J.-R. Lin, R.-F. Lu, M.-C. Lin, and P.-Y. Wang, "Squeeze film characteristics of parallel circular disks lubricated by ferrofluids with non-Newtonian couple stresses," Tribology International, vol. 61, pp. 56-61, 2013.

[4] S. T. Tzeng and E. Saibel, "Surface roughness effect on slider bearing lubrication," ASLE Transactions, vol. 10, pp. 334-342, 1967.

[5] H. Christensen and K. C. Tonder, "Tribology of rough surfaces: parametric study and comparison of lubrication models," Report 22/69-18, SINTEF, Trondheim, Norway, 1969.

[6] H. Christensen and K. C. Tonder, "Tribology of rough surfaces: stochastic models of hydrodynamic lubrication," SINTEF Report 10/69-18, 1969.
[7] H. Christensen and K. C. Tonder, "The hydrodynamic lubrication of rough bearing surfaces of finite width," in Proceedings of the ASME-ASLE Lubrication Conference, Paper no.70-Lub-7, Cincinnati, Ohio, USA, October 1970.

[8] B. L. Prajapati, "Squeeze film behaviour between rotating porous circular plates with a concentric circular pocket: surface roughness and elastic deformation effects," Wear, vol. 152, no. 2, pp. 301-307, 1992.

[9] J. L. Gupta and G. M. Deheri, "Effect of roughness on the behavior of squeeze film in a spherical bearing," Tribology Transactions, vol. 39, no. 1, pp. 99-102, 1996.

[10] P. I. Andharia, J. L. Gupta, and G. M. Deheri, "Effect of transverse surface roughness on the behavior of squeeze film in a spherical bearing," International Journal of Applied Mechanics and Engineering, vol. 4, pp. 19-24, 1999.

[11] P. I. Andharia, G. M. Deheri, and J. L. Gupta, "Effect of longitudinal surface roughness on the behavior of squeeze film in a spherical bearing," International Journal of Applied Mechanics and Engineering, vol. 6, no. 4, pp. 885-897, 2001.

[12] N. B. Naduvinamani, P. S. Hiremath, and G. Gurubasavaraj, "Effect of surface roughness on the couple-stress squeeze film between a sphere and a flat plate," Tribology International, vol. 38, no. 5, pp. 451-458, 2005.

[13] T. Pylios and D. E. T. Shepherd, "Prediction of lubrication regimes in wrist implants with spherical bearing surfaces," Journal of Biomechanics, vol. 37, no. 3, pp. 405-411, 2004.

[14] J. Zueco and O. A. Bég, "Network numerical analysis of hydromagnetic squeeze film flow dynamics between two parallel rotating disks with induced magnetic field effects," Tribology International, vol. 43, no. 3, pp. 532-543, 2010.

[15] J.-R. Lin, "Inertia force effects in the non-Newtonian couple stress squeeze film between a sphere and a flat plate," Tribology International, vol. 67, pp. 81-89, 2013.

[16] S. J. Patel and G. M. Deheri, "Ferrofluid lubrication of a squeeze film in rough porous parallel circular disks, considering slip velocity," Journal of Mechanical and Industrial Engineering Research, vol. 3, no. 2, pp. 9-24, 2014.

[17] G. S. Beavers and D. D. Joseph, "Boundary conditions at a naturally permeable wall," Journal of Fluid Mechanics, vol. 30, no. 01, pp. 197-207, 1967.

[18] W. Hai, "Effect of velocity-slip on the squeeze film between porous reactangular plates," Wear, vol. 20, no. 1, pp. 67-71, 1972.

[19] E. M. Sparrow, G. S. Beavers, and I. T. Hwang, "Effect of velocity slip on porous-walled squeeze films," Journal of Tribology, vol. 94, no. 3, pp. 260-264, 1972.

[20] J. Prakash and S. K. Vij, "Effect of velocity slip on the squeeze film between rotating porous annular discs," Wear, vol. 38, no. 1, pp. 73-85, 1976.

[21] K. C. Patel, "The hydromagnetic squeeze film between porous circular disks with velocity slip," Wear, vol. 58, no. 2, pp. 275281, 1980

[22] A. W. Yacout, A. S. Ismaeel, and S. Z. Kassab, “The combined effects of the centripetal inertia and the surface roughness on the hydrostatic thrust spherical bearings performance," Tribology International, vol. 40, no. 3, pp. 522-532, 2007.

[23] N. D. Patel and G. M. Deheri, "Effect of surface roughness on the performance of a magnetic fluid based parallel plate porous slider bearing with slip velocity," Journal of the Serbian Society for Computational Mechanics, vol. 5, no. 1, pp. 104-118, 2011.

[24] R. U. Patel and G. M. Deheri, "Effect of slip velocity on the performance of a short bearing lubricated with a magnetic fluid," 
Acta Polytechnica, Journal of Advanced Engineering, vol. 53, no. 6, pp. 890-894, 2013.

[25] J. R. Patel and G. M. Deheri, "Effect of slip velocity and roughness on the performance of Jenkins model based on magnetic squeeze film in curved rough circular plates," Journal of the Serbian Society for Computational Mechanics, vol. 8, no. 1, pp. 45-63, 2014.

[26] J. R. Patel and G. M. Deheri, "Combined effect of surface roughness and slip velocity on Jenkins model based magnetic squeeze film in curved rough circular plates," International Journal of Computational Mathematics, vol. 2014, Article ID 367618, 9 pages, 2014.

[27] G. M. Deheri, S. J. Patel, and J. R. Patel, "Effect of surface roughness on a magnetic squeeze film for a sphere in a spherical seat," Journal of the Serbian Society for Computational Mechanics, vol. 8, no. 2, pp. 1-13, 2014.

[28] B. C. Majumdar, Introduction to Tribology of Bearings, S.Chand \& Company Ltd., New delhi, India, 2008.

[29] J. L. Neuringer and R. E. Rosensweig, "Magnetic fluid," Physics of Fluids, vol. 7, no. 12, pp. 19-27, 1964.

[30] M. V. Bhat, Lubrication with a Magnetic Fluid, Team Spirit Private Limited, Mumbai, India, 2003.

[31] B. L. Prajapati, On certain theoretical studies in hydrodynamic and electro-magneto-hydrodynamic lubrication [Ph.D. thesis], Sardar Patel University, Gujarat, India, 1995.

[32] B. Bhushan, Introduction to Tribology, John Wiley \& Sons, 2002. 

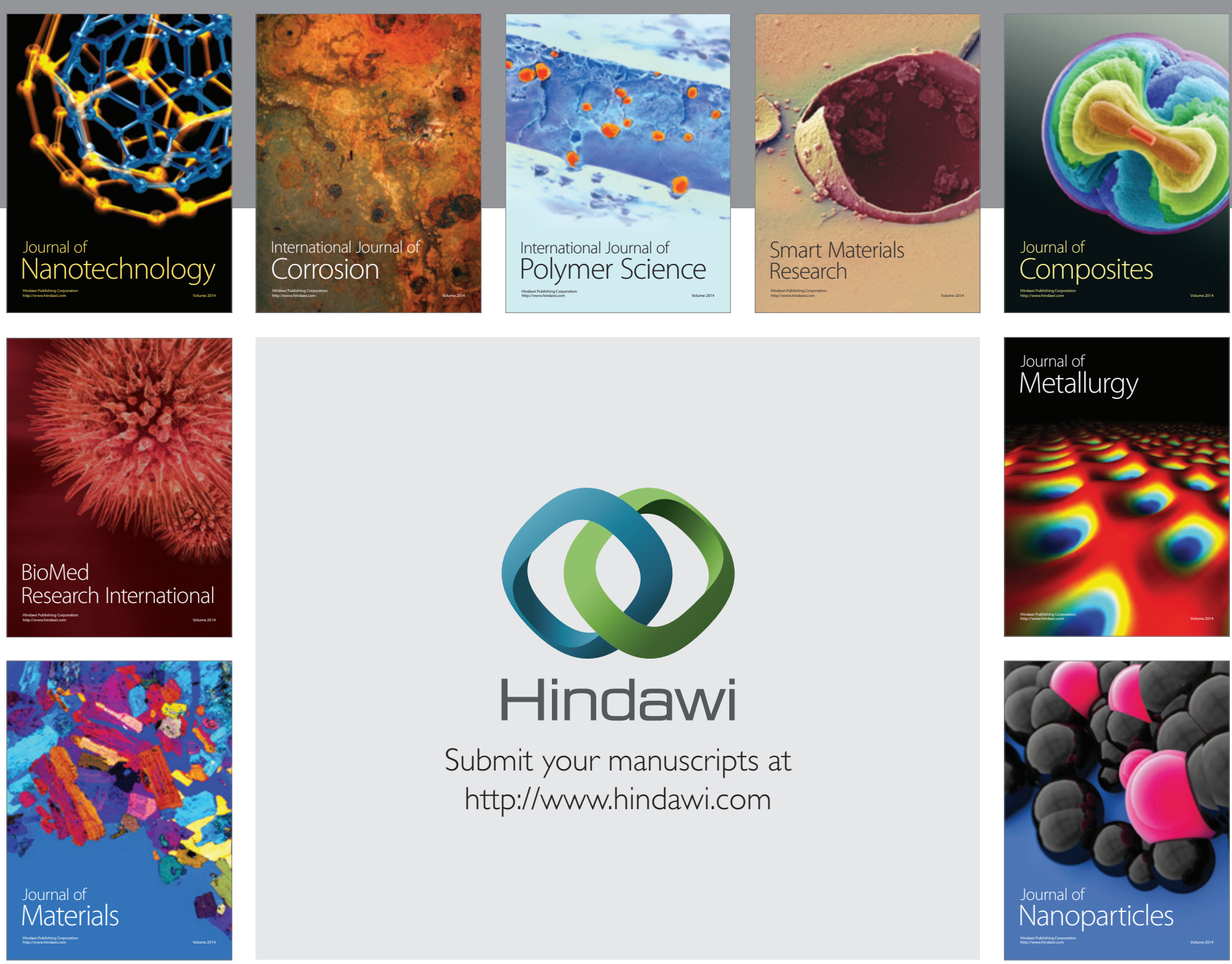

Submit your manuscripts at http://www.hindawi.com
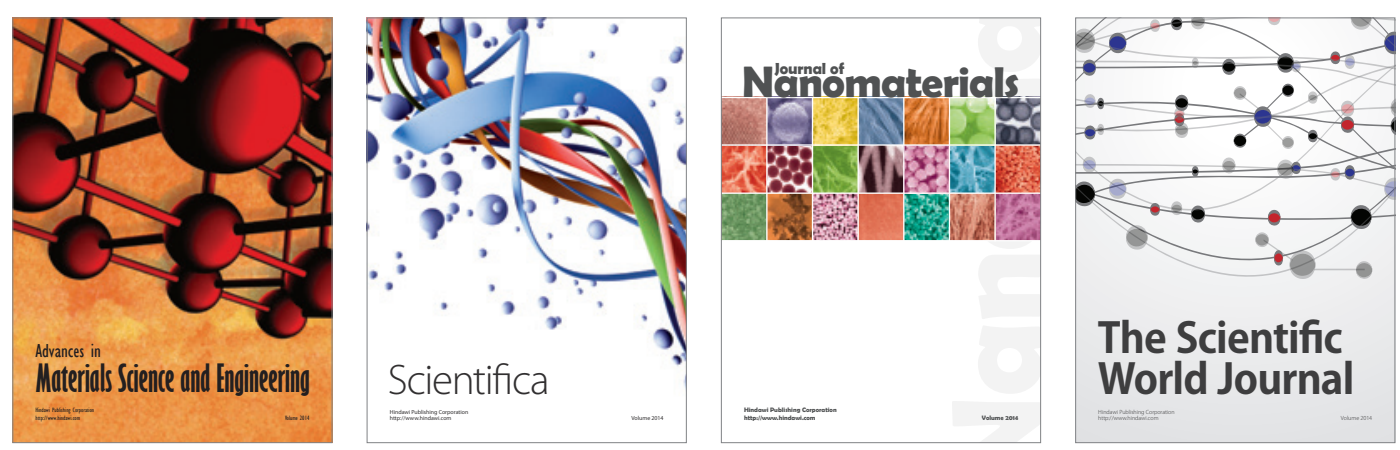

\section{The Scientific World Journal}
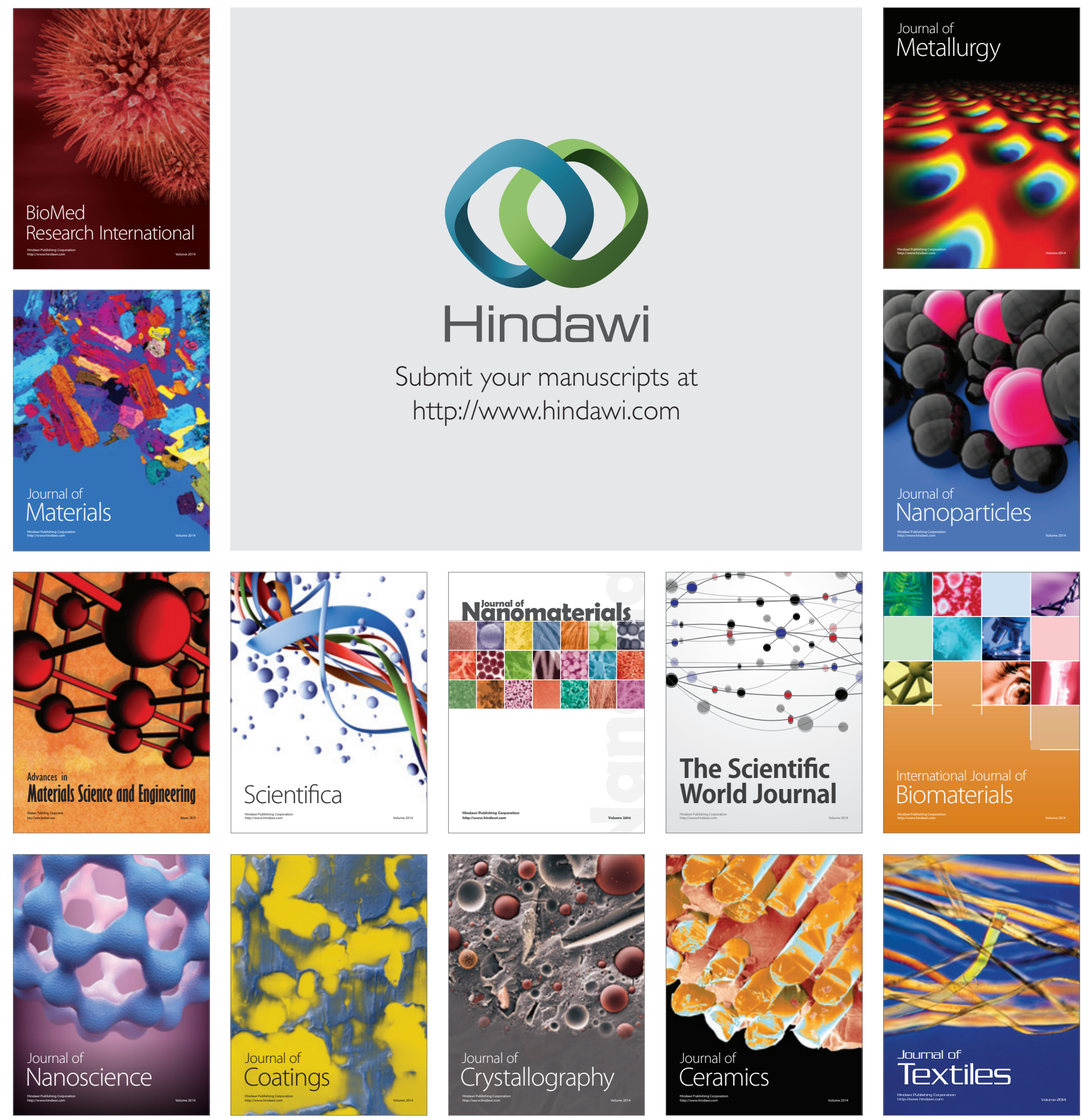